\title{
Open Scholarship Policies and Technologies: The European Research Library as a Model for Advancing Global Scholarly Communication
}

\section{Introduction}

Open scholarship is a culmination of many factors: the introduction to and reliance on technology for disseminating research, a push by governments toward transparency and citizen engagement, and a disruption of traditional models of sharing scholarly work. Current literature points to a need for policies, resource-intensive technologies, and buy-in from research funders, publishers, and scholarly societies and associations. Over time, libraries have become the locus around which these disruptions have incubated, due in no small part to an ethos of information access, and the technological turn in library infrastructure.

As a Fulbright-Schuman Innovation fellow, I would undertake a study of the information policy shifts in the European Union toward an "open scholarship" and examine those policies effects on the role of a research librarian. My goals in conducting this research project are to understand

- how information policy responds to cultural shifts,

- why libraries are at the center of this sea change, and

- how the global library community can develop models to push toward a more socially-just research ecosystem.

Employing my research interests in Europe at this critical moment for national and multinational information policy is the impetus behind my proposal.

\section{Background}

My first act as an information professional in 2011 was to draft a response to a Request for Information on Public Access to Scholarly Publications issued by the White House Office of Science and Technology Policy (OSTP). As a brand-new librarian focused in the area of digital academic publishing and open access, this assignment presented a challenge. I had to make the case that technological infrastructure was a reliable investment and represent specific concepts in language that could be generalized by policy makers. Informed by the flood of responses they received, the OSTP issued a directive in 2013 that shifted federally funded research data and publications toward open sharing online. That experience begat my interest in the interplay of public policy and information-sharing technologies.

Recognizing that cultural and political factors inform information habits, I employ methodologies and precepts from my graduate work in American Studies and Information Studies

- to explore the evolution of librarianship toward a research collaboration model focused on information processes and impacts, rather than solely providing access to resources like books, journals, and databases, and,

- to build the nascent field of "digital scholarship", including sub-fields like digital humanities, open access publishing, research data management and curation, and digital pedagogy. 
The combination of these research interests led to my invitation to the inaugural UNESCO-supported Open Scholarship Initiative meeting in 2015. I also served on the first Coordinating Committee for the Coalition of Open Access Policy Institutions from 2012-2015, developing a community for librarians working at the intersection of publishing, university-level open policies, and technological infrastructure. Over a relatively short career, I have developed a national profile for advancing librarianship into a technology-rich, community-engaged future.

\section{Project Detail}

I propose to embed myself within the University of Maastricht Libraries Research Support Programme and the Royal Danish Library to research the practices used by libraries to connect open scholarship policies to researchers.

- I will conduct a qualitative study on the librarian's decision-making processes for building support technologies and programs for open scholarship. What administrative and institutional structures allow for and/or hinder progressive models of research support?

- I will connect with stakeholders - research institutes, scholars, national/regional professional associations - to understand their evolving perceptions of the research library. What characteristics does the library represent for a campus moving toward open scholarship?

- I will interrogate the "imagined community" that is represented in the library and, at the macro level, through national open scholarship initiatives. How does imagined community create and/or channel the will and energy through which open scholarship is advancing?

My objectives are, first, to participate in the global community working to advance open scholarship, and second, to exchange models, tools, processes, and concepts that will better connect libraries in the United States and Europe with progressive information policies like net neutrality and open data.

My project will be enacted in two modes. 1) Participant observation will allow me to investigate the library community and the detailed ways technologies and technological tools are used to formalize open scholarship. I am particularly interested in the process-based research model Maastricht uses, and the Digital Social Science Lab at The Faculty Library at the University of Copenhagen. 2) Ethnographic interviews with stakeholders, including students, faculty, and administrators will provide the broader context in which this work occurs. Throughout, I will rely on my hosts to provide connections with organizations like LIBER, the association of European research libraries, conveniently located in the National Library of the Netherlands. I will research open scholarship policies and technologies in two entirely different national, political, social, and cultural contexts, while making connections between those implementing open scholarship, those producing scholarship, and the organizations and bodies creating the policies.

Throughout the study, I will contribute my expertise in building digital scholarship programs at research libraries, working with my hosts to identify some initiatives that I 
could pilot with them. My expertise in digital humanities will be helpful as the University of Maastricht recently published a report outlining a growth plan in that area.

Additionally, my training in the Data Carpentry method of teaching data analysis software and skills to non-specialists will be utilized both at Maastricht and at the Digital Social Sciences Lab.

\section{Project Timeline}

This study will span 4-6 months, starting at the beginning of the fall semester, 2018. Exact timelines would be finalized in consultation with my host institutions, in efforts to align with local events (i.e. symposia, conferences) and to maximize the effectiveness of my study and contributions.

\section{Significance}

The European Union is leading a global push toward open scholarship. The EU's Horizon 2020 statement lays out a "framework programme for research and innovation" including especially the area of "Open Science (open access)." The investment of time and resources directed toward this agenda is particularly appealing at a moment when science, inquiry, and openness seem to be undervalued in the political sphere in the United States. Additionally, centering this project in The Netherlands will be interesting because Elsevier, the largest STEM (Science, Technology, Engineering, Math) publisher in the world, is a Dutch company and has financial interests often at cross purposes from open scholarship movements. Ongoing negotiations between Elsevier and EU members will alter the future of academic publishing and open scholarship. The economic impact of the evolving publishing industry is an additional draw for me.

This study will be significant by providing a roadmap for connecting civic life to research culture and processes. The political culture in the U.S. necessitates libraries to advance accurate information and diverse research. Looking to our European colleagues for cross-collaborative ideas will inform these aspirations. The Netherlands and Denmark will benefit from my history and involvement with national coalitions and working groups. Although the U.S. is lagging behind the EU in this area, I will provide an alternate point of view that will generate critical discourse about the global nature of this work we share. An "on the ground" perspective will allow me to better understand my own research and praxis of librarianship.

This is the ideal time for this project because the Netherlands, Denmark, and other EU members, are quickening their pace to meet the charge of the Horizon 2020 plan. Undertaking this study, at this specific moment, is central to my continued research on how libraries respond to political shifts and technological innovations. While many other countries are working to advance open policies, my proposal seeks primary placement in the Netherlands because of the breadth of policy, resources, and infrastructure already in motion, like the forthcoming development of a European Open Science Cloud, in which The Netherlands plays a significant role.

\section{Significance of Hosts}


Maastricht is ideal for my study because of its character as an international-focused, innovation-prone institution of higher education, on a trajectory similar to that of my home institution at Florida State University. Their status as the sole Dutch university in the Worldwide Universities Network and campus-wide research theme focusing on "Europe and a Globalising World," and specifically the impact of technological developments, will also contribute to my project's success. Due to this focus, English is spoken widely, decreasing a language gap between students, faculty, and staff. An affiliation with United Nations University - Maastricht Economic and social Research institute on Innovation and Technology (UNU-MERIT), which "explores the social, political and economic factors that drive technological innovation, with a particular focus on creation, diffusion and access to knowledge," will provide an additional knowledge community that I would participate in through symposia, workshops, or public talks.

As open scholarship initiatives tend to focus on STEM research, time spent in Denmark at the Digital Social Science Lab will expand and complement my project. In what ways is an innovative, creative physical space helpful for inspiring new kinds of open scholarly work? The affiliation with the Royal Library will also allow me to trace the connection between a national library and open scholarship policies. Tying academic research, public libraries, and national cultural heritage together in one organization is an innovative model, and will deepen the scope of my research there.

\section{Outputs}

The products of my research study will be 1) a conceptual framework for open scholarship support (based on the Research Lifecycle, see Appendix A), 2) a praxis-focused toolkit, and 3) a peer-reviewed research article. Due to the nature of my work as a librarian, the creation of a "policy to praxis" toolkit will be critical to my project's broad applicability. Developing a toolkit on open scholarship policies in implementation, with a global perspective will be useful for librarians' research and vocational practice. As an "open scholar" myself, all of the outcomes and products of my research will be fully open online for anyone to read, reuse, and adapt.

\section{Conclusion}

The combination of all the available resources, national and EU pushes toward open scholarship, Maastricht's model of library services, the Royal Library of Denmark's support of the Digital Social Science Lab, and my years of work advocating for open national policies in the U.S. assures me that this project is feasible, necessary, and relevant. The opportunity to serve as a Fulbright ambassador will foster a deeper connection between the EU and U.S., especially in the areas of research, public policy, and technology infrastructure. I believe this study is an essential next step in my professional, personal, and cultural development. I expect to build bridges with my colleagues abroad, which will continue beyond the project timeline. I look forward to the multitude of ways this experience will benefit the often underserved global scholarly community who seek access to rigorous scholarship online. 